\title{
Evaluation of patients with displasia of hip development, radiographic and functional results
}

\section{Introduction}

Hip development dysplasia (DDH) is one of the most common problems in Pediatric Orthopedics; It covers a broad spectrum that ranges from simple neonatal instability to dislocation of the hip, where there is inadequate development of the acetabulum, the femoral head, or both. ${ }^{1-4}$ The incidence is variable and ranges from $0.1 \%$ per 1000 in Chinese, to 75 per 1,000 in Yugoslavia, the incidence in Mexico is 1.5 per 1,000 live births..$^{5-10}$

\section{Objective}

The objective of the present study was to perform a statistics of the patients seen in the outpatient clinic of the Miguel Hidalgo Hospital Centennial during the period from June 2016 to July 2017, first to know the prevalence of hip development dysplasia, as well as the average diagnosis age and treatment and its current status.

\section{Material and methods}

We performed a retrospective analysis to determine the incidence of dysplasia of the hip development in patients seen in the outpatient clinic in the period of June 2016 and July 2017. We searched the records of the external consultation. The data recovered included the age of the patient at his first clinical appointment, the initial treatment, the initial and final acetabular index (Figure 1), the duration of treatment and the current status of the patients. The excluded patients were those patients with dysplasia of the teratological hip development and the patients who did not attend their follow-up, who had an incomplete file, as well as the patients who could not be located to assess their initial radiographs.

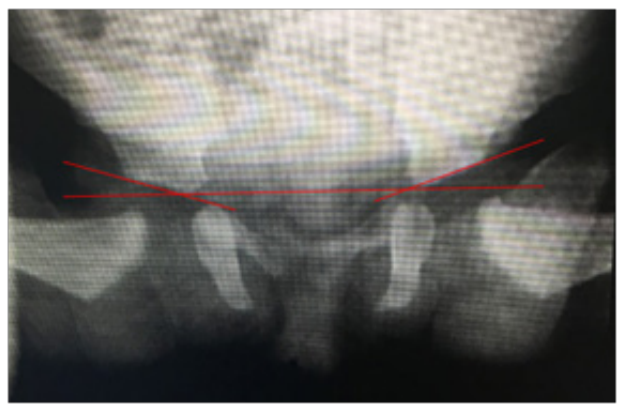

Figure I Radiography in the position of von Rosen, illustrating the measurement of the acetabular index.

\section{Results}

A database was made in the SPSS program version 21.0 to perform descriptive statistics using measures of central tendency, dispersion measures, frequency tables and percentages, as well as univariate and bivariate analyzes. The number of patients with congenital hip dislocation recorded in the study period was 116 , finding 33 patients with incomplete records, 12 patients with teratologic dysplasia, so the study only included 71 patients who met the inclusion criteria. The distribution by age with an average of 3 months, with $50 \%$ of patients in the first 3 months of life. Female sex predominated with 55 patients
Volume II Issue I - 2019

\author{
Lydia Alessandra Reyes Hernández,' Jorge \\ Enrique Cervantes Gudiño \\ 'Médico Residente de cuarto año de la especialidad de \\ Traumatología y Ortopedia del Centenario Hospital Miguel \\ Hidalgo, Mexico \\ ${ }^{2}$ Médico adscrito del servicio de Traumatología y Ortopedia del \\ Centenario Hospital Miguel Hidalgo, Mexico
}

\begin{abstract}
Correspondence: Lydia Alessandra Reyes Hernández Médico Residente de cuarto año de la especialidad de Traumatología y Ortopedia del Centenario Hospital Miguel Hidalgo, Av. Ferrocarril S/N, Alameda, 20259 Aguascalientes, Mexico, Tel 0I(52)8I I5I49323,Email lydia_reyes88@hotmail.com
\end{abstract}

Received: January 25, 2018 | Published: January 28, 2019

(78\%) and males with only 16 patients $(22 \%)$. The condition was bilateral in 33 patients $(46.5 \%)$ and unilateral in 38 patients $(53.5 \%)$, with predominance of affection of the left hip with 27 (71\%), right in $11(29 \%)$ (Table 1), giving a total of 71 hips studied. It was found that the initial treatment in most of the patients was pavlik harness with 34 patients (34.5\%) (Figure 2), followed by MAP + RC + Fiberglass with 14 patients $(14.2 \%)$, with 13 patients started with MAP + RA + Cotiloplasty (13.8\%), 5 patients with Denis Brown splint (5.7\%) and 5 patients only in vigilance for unstable hips without requiring any treatment $(5.7 \%)$ (Table 2).

Table I Total of studied patients

\section{Patients with DDH}

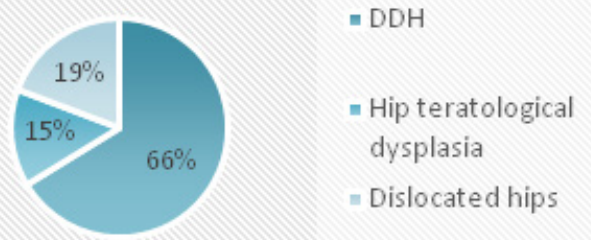

Table 2 Initial treatment of patients seen in the outpatient clinic

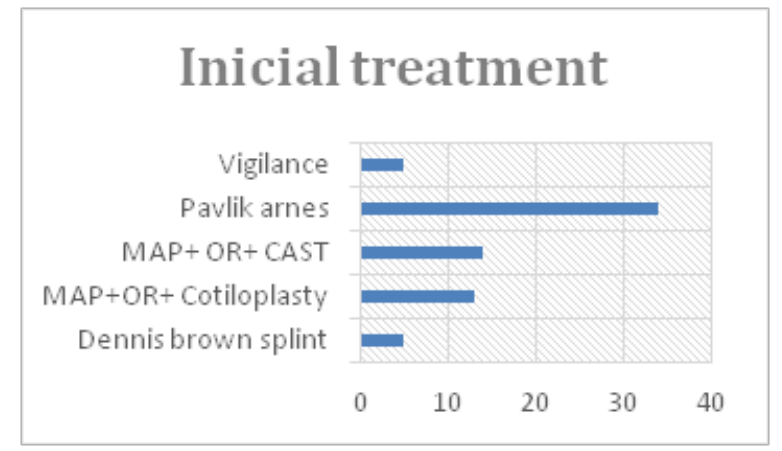

Of the patients initially treated with pavlik harness only 3 patients had recurrences $(8 \%)$ and of the 14 patients initially treated with MAP 
$+\mathrm{CR}+$ glass fibers 9 of them required a subsequent treatment (64\%) (Table 3). The posterior treatments in the case of the MAP + RA + Fiberglass fibers, the following treatment in 2 patients and 1 patient required only dennis brown nocturnal splints, and in the 9 patients with MAP + RC + fiberglass, the recurrence was $100 . \%$ required Cotiloplasty in a second treatment (Table 3).

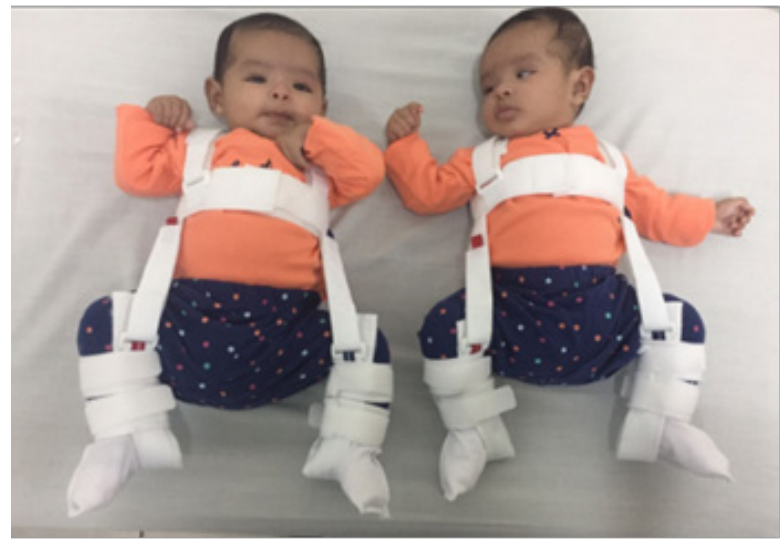

Figure 2 Patients using pavlik harness.

Table 3 Recurrences after initial treatment

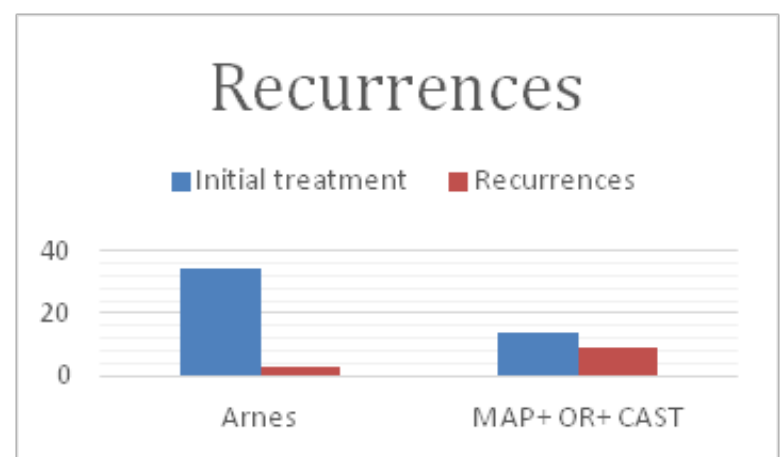

During the follow-up, 58 patients were only kept under surveillance $(58.8 \%), 5$ patients continued with the use of harness $(5.7 \%)$ and 5 patients maintained with Dennis Brown's splints (5.7\%), 1 patient still undergoing treatment. with glass fibers $(1.1 \%)$ and 2 patients are preparing to perform the cotiloplasty $(2.3 \%)$. Regarding radiographic results, we found a decrease in the acetabular index of 2.4 for the right side and 4.06 in the left acetabular index, without finding an improvement in terms of joint congruency.

\section{Conclusion}

In the present study it was found that as the patients' age of diagnosis was lower, the initial treatment was performed with Pavlik harnesses being the most economical and effective treatment, finding obvious radiographic improvement. As the age of diagnosis of our patients increases, the initial treatment is invasive and in the majority of cases a second treatment is required. Therefore, it is emphasized in the initial physical examination of the patient and in case of doubts in the diagnosis to keep them under surveillance in order to avoid the long-term consequences of this disease.

\section{Acknowledgment}

None.

\section{Conflicts of interest}

Authors declare that there is no conflicts of interest.

\section{References}

1. Bourne RB. Developmental dislocation of the hip: natural history, results of treatment and controversies. In: Controversies in Hip Surgery. Oxford: University Press; 2003. p. 2.

2. Rosendahl K, Markestad T, Lie R. Developmental dysplasia of the hip: a population-based comparison of ultrasound and clinical findings. Acta Paediatr. 1996;85(1):64-69.

3. Hiertonn T, James U. Congenital dislocation of the hip: experiences of early diagnosis and treatment. J Bone Joint Surg Br. 1968;50(3):542545 .

4. Tachdjian. Ortopedia pediátrica. Madrid, Marban, 2003;322-372.

5. Luis E. Montes, Rufino Menchaca. Displasia del desarrollo de cadera: Conocimientos en médicos pediatras. Acta Ortopedica Mexicana. 2009;23(1):22-25.

6. Morcuende JA, Weinstein SL. Developmental dysplasia of the hip: natural history, results of treatment, and controversies. In: Bourne R, ed. Controversies in Hip Surgery. Oxford, UK: Oxford University Press; 2003.

7. Mubarak S, Garfin S, Vance R, et al. Pitfalls in the use of Pavlik harness for the treatment of congenital dysplasia, subluxation and dislocation of the hip. J Bone Joint Surg Am. 1981;63(8):1239-1248.

8. Viere RG, Birch JG, Herring JA, et al. Use of the Pavlik harness in congenital dislocation of the hip. Analysis of failures of treatment. $J$ Bone Joint Surg Am. 1990;72(2):238-244.

9. Killian G, Hoffman EB. One stage treatment of congenital dislocation of the hip in older children. J Bone Joint Surg Br. 1997; 79B(4S):444.

10. Teloken M. Current concepts review. Reduction of congenital dislocation of the hip. J Bone Joint Surg. 1992;74(10);624-631. 